\title{
Multiple Pathologies are Common in Alzheimer Patients in Clinical Trials
}

\author{
B.W. Wang, E. Lu, I.R.A. Mackenzie, M. Assaly, C. Jacova, P.E. Lee, B.L. Beattie, \\ G.Y.R. Hsiung
}

\begin{abstract}
Objective: To determine the frequency of multiple pathology [Alzheimer Disease (AD) plus Vascular Dementia and/or Dementia with Lewy Bodies] in patients enrolled in clinical trials of AD therapy, and to compare the cognitive and functional assessments between patients with pure AD and AD with multiple pathology. Methods: We conducted a retrospective analysis of patients with a clinical diagnosis of AD who were enrolled in AD therapy clinical trials and subsequently received an autopsy for confirmation of their diagnosis from 2000 to 2009. Performance on cognitive screening tests, namely Modified Mini Mental State (3MS) exam, Mini Mental State Exam (MMSE) and Functional Rating Scale (FRS) were compared between patients with pure AD and multiple pathology. Results: Autopsy reports were available for 16/47 (34\%) of deceased patients. Of these 16 patients, $5(31 \%)$ had pure AD pathology, 10 $(63 \%)$ had AD with other pathology, and $1(6 \%)$ had non-AD pathology. Compared to patients with pure AD, patients with AD mixed with other pathology had poorer baseline FRS in problem-solving $(\mathrm{p}<0.01)$ and community affairs $(\mathrm{p}<0.02)$. Conclusion: While the strict enrollment criteria for clinical trials identified the presence of AD pathology in the majority of cases (15/16), multiple pathology was more common than pure AD in our series of autopsied patients. Premortem biomarkers that can distinguish between pure AD and $\mathrm{AD}$ with multiple pathology will be beneficial in future clinical trials and dementia patient management.
\end{abstract}

RÉSUMÉ: Les patients atteints de la maladie d'Alzheimer qui participent à des études cliniques sont souvent porteurs de pathologies multiples. Objectif : Le but de l'étude était de déterminer la fréquence de la présence de pathologies multiples [maladie d'Alzheimer (MA) et démence vasculaire et/ou démence à corps de Lewy] chez les patients qui participent à des études cliniques portant sur le traitement de la MA et de comparer les évaluations cognitives et fonctionnelles entre les patients présentant une MA pure et une MA associée à des pathologies multiples. Méthode : Nous avons procédé à une analyse rétrospective de patients, chez qui un diagnostic de MA avait été posé et qui ont participé à des études cliniques sur la MA, qui ont eu une autopsie par la suite pour confirmer le diagnostic entre 2000 et 2009. La performance aux tests de dépistage cognitif, soit le mini-examen modifié de l'état mental (Modified Mini Mental, 3MS), le mini-examen de l'état mental (Mini Mental State Exam, MMSE) et l'Échelle d'évaluation fonctionnelle (ÉEF) a été comparée entre les patients atteint d'une MA pure et ceux atteints de pathologies multiples. Résultats : Un rapport d'autopsie était disponible chez 16 des 47 patients décédés (34\%). Parmi ces 16 patients, 5 (31\%) avaient une MA pure au point de vue anatomopathologique, 10 (63\%) avaient une MA associée à une autre pathologie et $1(6 \%)$ avait une pathologie autre que la MA. Par rapport aux patients atteints d'une MA pure, les patients atteints de la MA associée à une autre pathologie avaient un score à l'ÉEF initiale plus faible pour la résolution de problèmes $(\mathrm{p}<0,01)$ et la participation à la vie communautaire $(\mathrm{p}<0,02)$. Conclusion : Bien que les critères de sélection stricts dans les études cliniques identifiaient la présence de la pathologie de la MA chez la majorité des patients (15/16), la présence de pathologies multiples était plus fréquente que la MA pure à l'autopsie dans cette série de patients. Des biomarqueurs qui peuvent distinguer la MA pure de la MA associée à des pathologies multiples du vivant du patient seront fort utiles pour les études cliniques à venir ainsi que pour le traitement des patients.

Can J Neurol Sci. 2012; 39: 592-599

Patients with dementia from multiple pathology often have a combination of Alzheimer's disease (AD) co-existing with Vascular Dementia (VaD) and/or Dementia with Lewy Bodies (DLB). Mixed AD, that is, AD co-existing with other pathology, is increasingly being recognized in clinical practice with an estimated prevalence of over $50 \%$ in community-dwelling dementia patients. ${ }^{1-3} \mathrm{AD}$ typically involves marked anterograde amnesia, whereas $\mathrm{VaD}$ is often characterized by focal neurological symptoms, abrupt or stepwise progression, executive dysfunction and psychomotor slowing. ${ }^{4}$ By contrast, DLB is commonly associated with fluctuating cognition with variable attention and alertness, visual perceptual disturbances or hallucinations, and early extrapyramidal symptoms, as well as rapid eye movement (REM) sleep disturbances and neuroleptics sensitivity. ${ }^{5}$ There are no universally accepted diagnostic criteria for mixed $\mathrm{AD}$, but a definition within a broad lexicon of $\mathrm{AD}$ has recently been proposed. ${ }^{6}$ Neuropsychological features of the various dementia entities often overlap, and clinical phenotypes, especially in those with mixed pathology, remain uncertain. Therefore, it is conceivable that patients with mixed AD may be enrolled in clinical trials of AD therapy intended for patients

From the Department of Medicine (BWW, EL, MA, CJ, PEL, BLB, GYRH), Faculty of Medicine, University of British Columbia; Department of Pathology and Laboratory Medicine (IRAM), Vancouver General Hospital, Vancouver, British Columbia, Canada. Received January 10, 2012. Final Revisions Submitted April 3, 2012.

Correspondence to: Ging-Yuek Robin Hsiung, Division of Neurology, Room S162, 2211 Wesbrook Mall, University of British Columbia, Vancouver, British Columbia, V6T 2B5, Canada. Email: hsiung@mail.ubc.ca. 
with pure AD pathology, which may have important implications on outcome of the trials. However, systematic autopsy studies on AD patients who had participated in clinical trials are rare, and tend to be specific to a type of intervention. ${ }^{7,8}$ In the current study, we investigated the prevalence and cognitive performance of patients with pure $\mathrm{AD}$ and $\mathrm{AD}$ with multiple pathologies who participated in clinical trials of AD therapy at our center over a nine-year period.

\section{METHODS}

We conducted a retrospective review using clinical and autopsy data collected over nine years between September 2002 and August 2011 at the University of British Columbia Hospital Clinic for Alzheimer's Disease and Related Disorders (UBCHCARD), a tertiary dementia clinic staffed by subspecialty trained neurologists and geriatricians. All patients enrolled in AD clinical trial protocols met strict inclusion/exclusion criteria; subjects needed to: (i) be 50 years or older (ii) meet the National Institute of Neurological and Communicative Disorders and Stroke and the Alzheimer's Disease and Related Disorders Association (NINCDS -- ADRDA) criteria for the diagnosis of probable $\mathrm{AD}^{9}$ and (iii) have no existing comorbid psychiatric illnesses (major depressive disorder, psychosis, bipolar disorder), unstable systemic illnesses (e.g. uncontrolled diabetes or cardiovascular disease) or other suspected causes of cognitive impairment (i.e. other non-AD neurological diseases, stroke, brain tumor or delirium).

\section{Clinical data collection}

Our institutional Clinical Research Ethics Board and the Vancouver Coastal Health Research Institute have approved the study and written consent for study participation and autopsy was obtained from all patients. Patients' medical histories were systematically documented by $\mathrm{AD} /$ dementia specialist geriatricians or neurologists. Demographics included age at first visit, sex, and level of education. Clinical characteristics included duration of symptoms documented at first visit, age of death, time from symptom onset to death, family history of dementia, depression before symptom onset, and vascular risk factors including smoking. Standardized scales including the Mini Mental State Examination (MMSE), Modified Mini Mental State (3MS) examination and Functional Rating Scale (FRS) were administered at every clinical visit until they reached a floor effect (i.e. MMSE <5). The FRS is a clinician-administered scale modeled after the Clinical Dementia Rating scale (CDR) to assess four cognition-based (memory, language, problem solving, and orientation) and four non-cognitive (community affairs, home and hobbies, personal care and affect) dimensions. ${ }^{10}$ The rater takes into account the clinical assessment and interview with the patient and caregiver to provide a score on each functional dimension based on a scale from 1 (healthy/normal) to 5 (severe impairment). A high concordance with the CDR score has been demonstrated in the assessment of patients with $\mathrm{AD}$ and vascular cognitive impairment, and an estimate of the CDR sum of box score can be derived from the FRS. ${ }^{11}$ In addition, all patients had either computed tomogram (CT) (with or without contrast) or magnetic resonance imaging (MRI) to screen for reversible causes of cognitive impairment.

\section{Neuropathology procedure and criteria}

Subjects who were involved in clinical trials at UBCHCARD were also followed by staff geriatricians or neurologists on an outpatient basis. The option of having a brain autopsy was offered to all patients with a follow-up letter of consent mailed to patients and/or caregivers and re-confirmed with next of kin at the time of autopsy. In this study and from our previous experience, approximately one in three subjects would agree to this option. Neuropathologists were not blinded to patient clinical data and had full access to health records and imaging findings (CT/MRI) on all autopsied subjects, as it was felt to be required for the pathologist to produce a more comprehensive pathology assessment, and certain pathological diagnostic criteria require correlation with clinical symptoms in order to make a probabilistic estimate. In all cases, neuropathological examinations followed a standardized protocol in which semiquantitative assessment of a wide range of pathological changes was performed systematically. ${ }^{12,13}$ The protocol was designed to be as unbiased as possible and not presuppose that one type of pathology would have a greater influence on the clinical presentation than another. Therefore, each type of pathology was graded independently and a judgment was made as to whether or not it was of sufficient severity to have independently caused dementia or contributed to dementia in an additive fashion. Thus, the neuropathological examinations included the following possible outcomes: pure $\mathrm{AD}, \mathrm{AD} / \mathrm{VaD}, \mathrm{AD} / \mathrm{DLB}$, $\mathrm{AD} / \mathrm{VaD} / \mathrm{DLB}, \mathrm{AD} /$ Other pathology, and other pathology. After formalin fixation, the weight of the brain was recorded and a gross examination of the external surface and cut sections was performed. Any focal lesions, the degree of atrophy of normal anatomical structures and the degree and pattern of ventricular enlargement were recorded. After an external examination of the whole brain was completed, coronal slices were taken at $1 \mathrm{~cm}$ intervals of the hemispheres, while the brainstem was sliced perpendicular to its axis at $0.5 \mathrm{~cm}$ intervals. Tissue sections for histology were taken from standardized anatomical regions that included the neocortical regions used in the CERAD protocol (superior and medial temporal gyri, middle frontal gyrus, inferior parietal lobule as well as the hippocampus, entorhinal cortex and midbrain). ${ }^{14}$ Additional tissue blocks were taken from regions where gross focal lesions were seen. A diagnosis of AD was given when numerous or moderate neuritic senile plaques (SP) and numerous or moderate neurofibrillary tangles (NFT) were present in the neocortex, fulfilling the NIA Reagan Criteria for a high or intermediate likelihood of AD ${ }^{15}$ Cases with absent or sparse SP and absent or sparse NFT were not given an AD diagnosis. Cortical Lewy Bodies (LB) were quantified according to the original consensus criteria for DLB.${ }^{16} \mathrm{~A}$ diagnosis of DLB was given when LB were present in the limbic and/or neocortex. The presence of LBs in the amygdala only was not sufficient to make a diagnosis of DLB. For diagnosis of vascular causes of dementia, the size, number and anatomical location of all macroscopic and microscopic chronic infarcts and hemorrhages were recorded using a semi-quantitative grading system (none, mild, moderate, severe). Recent vascular disease (i.e. just prior to death) would not be considered relevant to dementia. Large vessel stenosis, arteriolosclerosis, cerebral amyloid angiopathy and white matter rarefaction/demyelination were all graded and taken into account when assessing the overall degree of cerebrovascular disease (CVD). ${ }^{17}$ 
Table 1: Characteristics of patients with pure and mixed AD pathology

\begin{tabular}{|c|c|c|c|c|c|}
\hline \multirow[t]{2}{*}{ Characteristic } & $\mathbf{A D} / \mathbf{V a D}^{\mathbf{a}}$ & AD/VaD/DLB ${ }^{b}$ & Mixed AD ${ }^{c}$ & Pure AD ${ }^{d}$ & p value ${ }^{e}$ \\
\hline & $(\mathrm{n}=7)$ & $(\mathrm{n}=2)$ & $(\mathrm{n}=10)$ & $(\mathrm{n}=5)$ & \\
\hline $\begin{array}{l}\text { Sex - male } \\
\mathrm{n}(\%)\end{array}$ & $2(29)$ & $1(50)$ & $3(30)$ & $4(80)$ & 0.12 \\
\hline \multicolumn{2}{|c|}{ Education level - post-secondary } & & & & 1.00 \\
\hline $\mathrm{n}(\%)$ & $2(29)$ & $1(50)$ & $3(30)$ & $2(40)$ & \\
\hline $\begin{array}{l}\text { Smoking history } \\
\mathrm{n}(\%)\end{array}$ & $3(43)$ & $2(100)$ & $5(50)$ & $4(80)$ & 0.58 \\
\hline \multicolumn{2}{|c|}{ Age at first visit to UBCH-CARD } & & & & 0.18 \\
\hline $\begin{array}{l}\text { Mean } \pm \mathrm{SD} \\
\text { (range) }\end{array}$ & $\begin{array}{l}71.7 \pm 8.6 \\
(58-84)\end{array}$ & $\begin{array}{l}61.5 \pm 7.8 \\
(56-67)\end{array}$ & $\begin{array}{l}69.1 \pm 8.7 \\
(56-84)\end{array}$ & $\begin{array}{l}61.2 \pm 11.5 \\
(50-78)\end{array}$ & \\
\hline \multicolumn{2}{|c|}{ Duration of symptoms at first visit } & & & & 0.67 \\
\hline $\begin{array}{l}\text { Mean } \pm \mathrm{SD} \\
\text { (range) }\end{array}$ & $\begin{array}{l}6.2 \pm 3.5 \\
(1-10)\end{array}$ & $\begin{array}{l}3.5 \pm 2.1 \\
(2-5)\end{array}$ & $\begin{array}{l}5.4 \pm 3.2 \\
(1-10)\end{array}$ & $\begin{array}{l}5.2 \pm 4.6 \\
(1-13)\end{array}$ & \\
\hline \multicolumn{2}{|l|}{ Age at death } & & & & 0.20 \\
\hline $\begin{array}{l}\text { Mean } \pm \text { SD } \\
\text { (range) }\end{array}$ & $\begin{array}{l}78.4 \pm 7.7 \\
(64-87)\end{array}$ & $\begin{array}{l}65.0 \pm 9.9 \\
(58-72)\end{array}$ & $\begin{array}{l}75.0 \pm 9.1 \\
(58-87)\end{array}$ & $\begin{array}{l}68.4 \pm 7.8 \\
(58-78)\end{array}$ & \\
\hline \multicolumn{2}{|c|}{ Time from symptom onset to death } & & & & 0.46 \\
\hline $\begin{array}{l}\text { Mean } \pm \mathrm{SD} \\
\text { (range) }\end{array}$ & $\begin{array}{l}12.9 \pm 3.8 \\
(8-17)\end{array}$ & $\begin{array}{l}7.0 \pm 0.0 \\
(7-7)\end{array}$ & $\begin{array}{l}11.1 \pm 4.0 \\
(7-17)\end{array}$ & $\begin{array}{l}12.4 \pm 3.3 \\
(8-17)\end{array}$ & \\
\hline \multicolumn{6}{|c|}{ Time from last assessment to death } \\
\hline $\begin{array}{l}\text { Mean } \pm \mathrm{SD} \\
\text { (range) }\end{array}$ & $\begin{array}{l}3.6 \pm 1.3 \\
(0-6)\end{array}$ & $\begin{array}{l}3.0 \pm 1.0 \\
(2-4)\end{array}$ & $\begin{array}{l}3.1 \pm 1.5 \\
(0-6)\end{array}$ & $\begin{array}{l}3.4 \pm 2.2 \\
(0-6)\end{array}$ & 0.44 \\
\hline \multicolumn{2}{|c|}{ Family history of dementia } & & & & 1.00 \\
\hline $\mathrm{n}(\%)$ & $2(29)$ & $1(50)$ & $3(30)$ & $2(40)$ & \\
\hline \multicolumn{2}{|c|}{ Depression before symptom onset } & & & & 0.56 \\
\hline $\mathrm{n}(\%)$ & $1(14)$ & $1(50)$ & $2(20)$ & $2(40)$ & \\
\hline $\begin{array}{l}\text { Diabetes mellitus } \\
\mathrm{n}(\%)\end{array}$ & $0(0)$ & $0(0)$ & $0(0)$ & $2(40)$ & 0.10 \\
\hline $\begin{array}{l}\text { Hypertension } \\
\text { n (\%) }\end{array}$ & $4(57)$ & $1(50)$ & $5(50)$ & $1(20)$ & 0.58 \\
\hline $\begin{array}{l}\text { Hypercholesterolemia } \\
\text { n (\%) }\end{array}$ & $0(0)$ & $1(50)$ & $1(10)$ & $1(20)$ & 1.00 \\
\hline $\begin{array}{l}\text { Cardiovascular disease } \\
\mathrm{n}(\%)\end{array}$ & $1(14)$ & $0(0)$ & $1(10)$ & $0(0)$ & 1.00 \\
\hline
\end{tabular}

AD, Alzheimer's disease; VaD, vascular dementia; DLB, dementia with Lewy bodies; UBCH-CARD, University of British

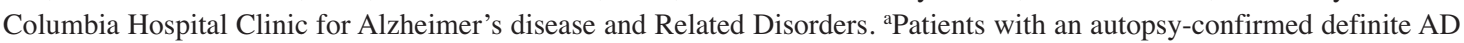
(Reagan criteria $)^{4}$ and vascular dementia (VaD) with (i) significant subcortical small vessels white matter ischemic injury $(>25 \mathrm{~mL}$ in total volume), and/or (ii) frequent $(>5)$ smaller chronic lesions or lacunes $(<15 \mathrm{~mm})$ affecting multiple anatomical regions of both hemispheres, excluding large vessels cortical strokes, "strategic" strokes, or hemorrhagic strokes. ${ }^{\text {bPatients }}$ with autopsy-confirmed definite $\mathrm{AD}$, VaD and dementia with Lewy bodies (DLB). ${ }^{5}$ cPatients with AD/VaD $(\mathrm{n}=7)$ or $\mathrm{AD} / \mathrm{VaD} / \mathrm{DLB}(\mathrm{n}=2)$ or $\mathrm{AD} /$ hydrocephalus/inflammatory pseudotumor $(\mathrm{n}=1)$. ${ }^{\mathrm{d}}$ Patients with an autopsy-confirmed definite $\mathrm{AD}$ (Reagan criteria) ${ }^{4}$ and no other significant dementia-related pathology. ${ }^{e}$ pure $\mathrm{AD}$ vs. mixed $\mathrm{AD}$ 
The following patterns of CVD were considered to have possibly caused or contributed to dementia:

a) single large chronic cerebral infarcts;

b) numerous smaller chronic lesions affecting multiple anatomical regions of both hemispheres;

c) lesions affecting critical anatomical structures (e.g.

bilateral hippocampi);

d) extensive ischemic injury to subcortical white matter and thus leading to a pathological diagnosis of CVD-related dementia.

\section{Statistics}

Demographics and clinical characteristics of patients with pure and mixed $\mathrm{AD}$ pathology (consisting of $\mathrm{AD} / \mathrm{VaD}$, $\mathrm{AD} / \mathrm{VaD} / \mathrm{DLB}$ and $\mathrm{AD} /$ other pathology) were compared using the Mann-Whitney U test for continuous variables, and Fisher's exact test for categorical variables with an expected count of 5 or less in 1 or more cells. Other outcomes of interest included the baseline and last clinical assessment in MMSE, 3MS, and FRS. Subgroups of patients with mixed AD pathology - specifically $\mathrm{AD} / \mathrm{VaD}, \mathrm{AD} / \mathrm{DLB}$ and $\mathrm{AD} / \mathrm{VaD} / \mathrm{DLB}$ - were also separately compared to patients with pure $\mathrm{AD}$. Outcomes were reported with $\mathrm{p}$ values and statistical significance was defined as a $\mathrm{p}$ $<0.05$. No adjustment was made for multiple comparisons in this exploratory study.

\section{RESULTS}

Autopsy data were available for 16 of the 47 deceased patients $(34 \%)$ who were previously enrolled in $\mathrm{AD}$ clinical trial protocols over the nine-year period. Basic demographic and clinical characteristics (age at death, gender, level of education, initial and final MMSE scores) were not significantly different between clinical trials subjects with and without autopsy done (data not shown). Of these 16 patients with autopsy data, AD pathology was present in 15 subjects (94\%). Specifically, five (31\%) had pure AD pathology, ten had mixed AD pathology and one $(6 \%)$ had non-AD dementia (argyrophilic grain disease with hippocampal sclerosis / neurofibrillary tangle dominant dementia). Within the ten patients with mixed AD pathology, seven had $\mathrm{AD} / \mathrm{VaD}$, two had $\mathrm{AD} / \mathrm{VaD} / \mathrm{DLB}$ and one had $\mathrm{AD}$ with hydrocephalus and an inflammatory pseudotumor but no significant mass effect. Those with VaD had multiple small deep lacunes or white matter ischemic changes, and none had large cortical strokes or hemorrhage. No patients in our series had AD/DLB only. Demographics and clinical characteristics were comparable between patients with pure and mixed AD pathology (Table 1), although patients with mixed AD had a trend towards older age on their first visit to the clinic (on average eight years).

Brain imaging data were available in all subjects (15 had CT, one had MRI) prior to time of death (average 7.4 years, median eight years, range 0-13). Two out of five subjects with pure AD

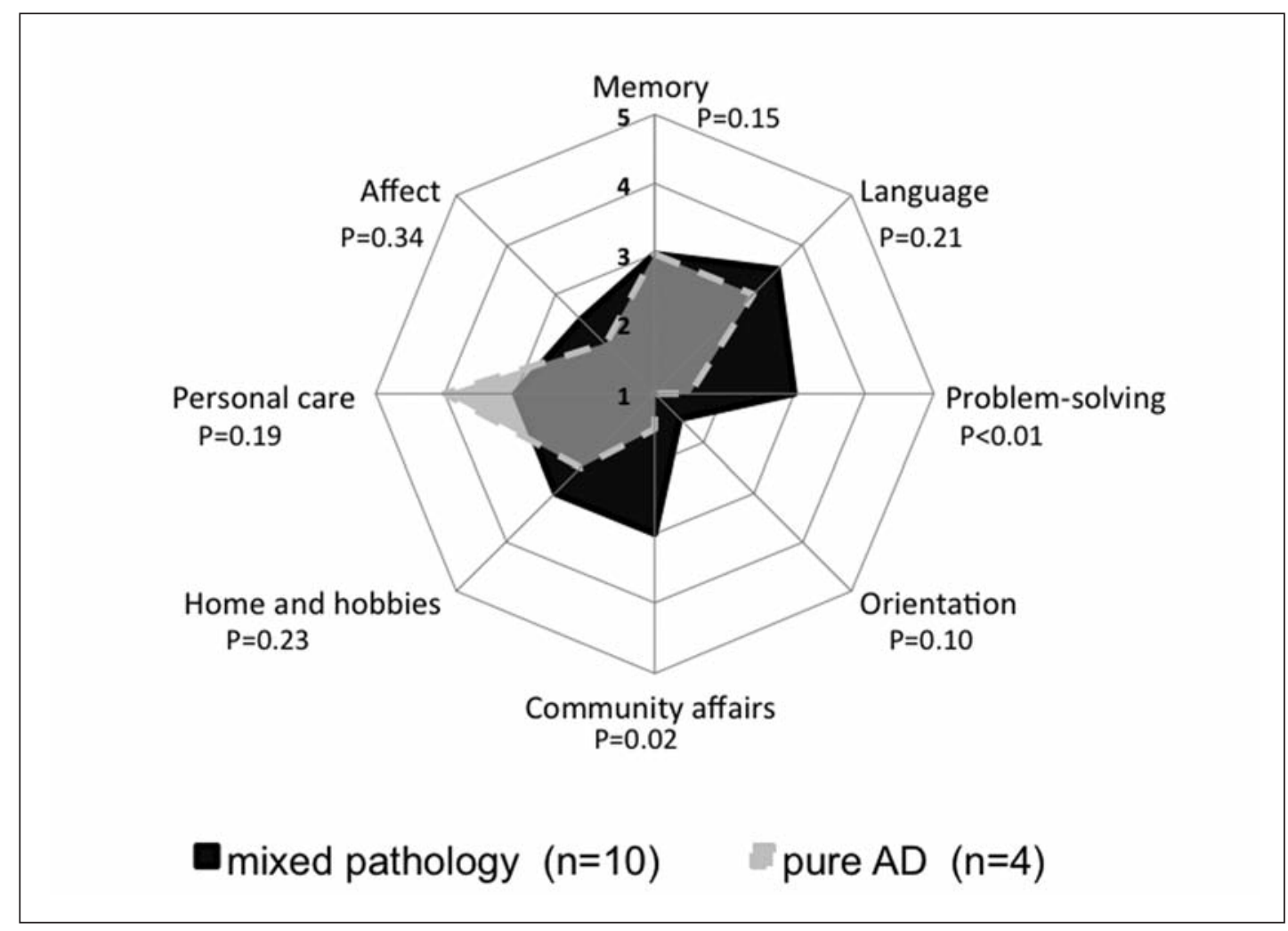

Figure: Baseline Functional Rating Score (FRS) in patients with pure and mixed Alzheimer's disease (AD) pathology. Higher number in the FRS represents worse performance. 
Table 2: Cognitive outcomes in patients with pure and mixed AD pathologyy

\begin{tabular}{|c|c|c|c|c|c|}
\hline Outcome & AD/VaD & AD/VaD/DLB & Mixed $\mathbf{A D}^{\mathbf{a}}$ & Pure AD & p value $^{\mathrm{b}}$ \\
\hline \multicolumn{6}{|c|}{ Modified Mini Mental State exam } \\
\hline Baseline $-\mathrm{n}$ & 6 & 1 & 8 & 4 & 0.09 \\
\hline Mean \pm SD & $74.8 \pm 19.0$ & $85.0 \pm 0.0$ & $77.3 \pm 16.6$ & $88.8 \pm 4.7$ & \\
\hline Median (range) & $80.5(38-91)$ & $85(85-85)$ & $83.5(38-91)$ & $90.5(82-92)$ & \\
\hline Final $-\mathrm{n}$ & 6 & 1 & 8 & 4 & 0.35 \\
\hline Mean \pm SD & $39.3 \pm 20.0$ & $60.0 \pm 0.0$ & $41.0 \pm 18.7$ & $58.3 \pm 31.4$ & \\
\hline Median (range) & $38.5(10-72)$ & $60(60-60)$ & $38.5(10-72)$ & $58(25-92)$ & \\
\hline \multicolumn{6}{|l|}{ Mini Mental State Exam } \\
\hline Baseline $-\mathrm{n}$ & 6 & 2 & 9 & 4 & 0.12 \\
\hline Mean \pm SD & $22.8 \pm 6.1$ & $24.5 \pm 0.7$ & $23.7 \pm 5.1$ & $27.0 \pm 1.8$ & \\
\hline Median (range) & $25(11-27)$ & $24.5(24-25)$ & $25(11-27)$ & $27(25-29)$ & \\
\hline Final $-\mathrm{n}$ & 6 & 2 & 9 & 4 & 0.44 \\
\hline Mean \pm SD & $14.3 \pm 4.2$ & $14 \pm 2.8$ & $13.7 \pm 3.9$ & $17.0 \pm 8.3$ & \\
\hline Median (range) & $13(10-22)$ & $14(12-16)$ & $13(9-22)$ & $17.5(7-26)$ & \\
\hline \multicolumn{6}{|l|}{ Functional Rating Scale } \\
\hline \multicolumn{6}{|l|}{ Total } \\
\hline Baseline $-\mathrm{n}$ & 7 & 2 & 10 & 4 & 0.07 \\
\hline Median (range) & $26(16-34)$ & $25.5(24-27)$ & $25(16-34)$ & $18.5(17-20)$ & \\
\hline Final $-\mathrm{n}$ & 6 & 2 & 9 & 4 & 0.27 \\
\hline Median (range) & $34(24-38)$ & $33.5(30-37)$ & $35(24-38)$ & $29.5(20-38)$ & \\
\hline \multicolumn{6}{|l|}{ Memory } \\
\hline Baseline & & & & & 0.15 \\
\hline Median (range) & $3(3-5)$ & $3.5(3-4)$ & $3(3-5)$ & $3(3-3)$ & \\
\hline Final & & & & & 0.73 \\
\hline Median (range) & $4.5(4-5)$ & $4(3-5)$ & $5(3-5)$ & $4.5(3-5)$ & \\
\hline \multicolumn{6}{|l|}{ Language } \\
\hline Baseline & & & & & 0.21 \\
\hline Median (range) & $4(2-5)$ & $3.5(3-4)$ & $3.5(2-5)$ & $3(3-3)$ & \\
\hline Final & & & & & 0.06 \\
\hline Median (range) & $5(4-5)$ & $5(5-5)$ & $5(4-5)$ & $4(3-5)$ & \\
\hline \multicolumn{6}{|l|}{ Problem solving } \\
\hline Baseline & & & & & $<0.01$ \\
\hline Median (range) & $3(2-5)$ & $3.5(3-4)$ & $3(2-5)$ & $2(1-2)$ & \\
\hline Final & & & & & 0.30 \\
\hline Median (range) & $4.5(4-5)$ & $4(4-4)$ & $4(4-5)$ & $4(2-5)$ & \\
\hline \multicolumn{6}{|l|}{ Orientation } \\
\hline Baseline & & & & & 0.10 \\
\hline Median (range) & $2(1-4)$ & $2(1-3)$ & $1.5(1-4)$ & $1(1-1)$ & \\
\hline Final & & & & & 0.15 \\
\hline Median (range) & $4(2-5)$ & $4(4-4)$ & $4(2-5)$ & $2.5(1-5)$ & \\
\hline \multicolumn{6}{|l|}{ Community affairs } \\
\hline Baseline & & & & & 0.02 \\
\hline Median (range) & $3(2-4)$ & $3(3-3)$ & $3(2-4)$ & $1.5(1-3)$ & \\
\hline Final & & & & & 0.68 \\
\hline Median (range) & $4(3-5)$ & $4(4-4)$ & $4(3-5)$ & $3(2-5)$ & \\
\hline \multicolumn{6}{|l|}{ Home and hobbies } \\
\hline Baseline & & & & & 0.23 \\
\hline Median (range) & $3(2-5)$ & $4(4-4)$ & $3(2-5)$ & $2.5(2-3)$ & \\
\hline Final & & & & & 0.67 \\
\hline Median (range) & $4.5(3-5)$ & $4.5(4-5)$ & $5(3-5)$ & $4.5(2-5)$ & \\
\hline \multicolumn{6}{|l|}{ Personal care } \\
\hline Baseline & & & & & 0.19 \\
\hline Median (range) & $3(2-4)$ & $4(4-4)$ & $3(2-4)$ & $4(3-4)$ & \\
\hline Final & & & & & 0.74 \\
\hline Median (range) & $3.5(2-4)$ & $4.5(4-5)$ & $4(2-5)$ & $3(3-5)$ & \\
\hline \multicolumn{6}{|l|}{ Affect } \\
\hline Baseline & & & & & 0.34 \\
\hline Median (range) & $3(1-4)$ & $2(1-3)$ & $2.5(1-4)$ & $2(1-2)$ & \\
\hline Final & & & & & 0.20 \\
\hline Median (range) & $4(2-5)$ & $3.5(2-5)$ & $4(2-5)$ & $3.5(2-4)$ & \\
\hline
\end{tabular}

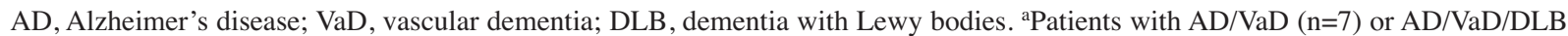
$(\mathrm{n}=2)$ or $\mathrm{AD} /$ hydrocephalus/inflammatory pseudotumor $(\mathrm{n}=1)$. ${ }^{\mathrm{b}}$ pure $\mathrm{AD}$ vs. mixed AD. 
had minimal white changes reported on brain imaging, and 4/10 subjects with $\mathrm{AD} / \mathrm{VaD}$ or $\mathrm{AD} / \mathrm{VaD} / \mathrm{DLB}$ had mild periventricular white matter changes on brain imaging documented at the time of initial clinical assessment. The rest of the subjects had no significant abnormality reported, other than atrophic changes.

Patients with mixed AD tended to have worse FRS scores (not statistically significant). They had significantly poorer baseline FRS in problem-solving $(\mathrm{p}<0.01)$ and community affairs $(\mathrm{p}<0.02)$ (Figure). Specifically, poorer baseline FRS was observed for patients with $\mathrm{AD} / \mathrm{VaD}$ in the categories of community affairs $(\mathrm{p}<0.04)$ and problem solving $(\mathrm{p}<0.02)$, compared to patients with pure AD. There is also a trend towards poorer FRS in the categories of home and hobbies $(p<0.05)$ and problem solving $(\mathrm{p}<0.05)$ for patients with $\mathrm{AD} / \mathrm{VaD} / \mathrm{DLB}$ (results not shown in Table 2). Comparisons of other baseline and final FRS, MMSE and 3MS performance were unremarkable (Table 2).

\section{Discussion}

This study confirmed that the current diagnostic methods and AD clinical trial enrollment criteria are effective for identifying AD pathology - our study had a 94\% (15/16) accuracy. However, only $31 \%$ of subjects had pure AD pathology, while mixed AD pathology was identified in the majority $(63 \%)$ of those who came to autopsy. Older age has been associated with a greater likelihood of developing mixed pathology, an observation we were able to make also in our cohort, though not statistically significant, presumably due to our small sample size. ${ }^{1,18}$ The high incidence of mixed dementia may also be due to referral bias of more complex cases to our tertiary dementia clinic, although any atypical clinical presentation of $\mathrm{AD}$ would likely have been excluded by the AD clinical trial exclusion criteria. Conversely, in the clinical trials setting, efforts are in place (i.e. imaging and Hachinski scores) to limit subjects with mixed pathology; therefore, the incidence of $\mathrm{AD}$ with mixed pathology may be even higher in the general population because the strict enrollment criteria would have excluded cases of mixed $\mathrm{AD}$ that presented with typical features of $\mathrm{VaD}$ or DLB. Interestingly, our findings are similar to the preliminary analysis of the Alzheimer's Disease Neuroimaging Initiative (ADNI) autopsy data, in which only $4 / 9(44 \%)$ was found to have pure $\mathrm{AD}$, with $5(55 \%)$ having $\mathrm{AD}$ mixed with other pathologies, including DLB, argyrophilic grain disease, and TDP-43. ${ }^{19}$

To our knowledge, this study is one of the first to compare the FRS scores between patients with pure and mixed AD pathology. Performance in the categories of problem solving and community affairs appears to be worse in patients with mixed AD pathology during the early stage of disease, as shown by baseline FRS. The presence of vascular and Lewy body pathology may interact synergistically with mild AD to cause greater functional impairment at the time of presentation. ${ }^{20}$ However, mixed pathology does not appear to affect the degree of cognitive impairment in patients during the later stages of dementia; neither MMSE nor 3MS scores could reliably differentiate between pure and mixed AD. This is consistent with several previous studies where significant overlap between the neuropsychological profiles of $\mathrm{AD}$ and cerebrovascular disease have been demonstrated..$^{21-24}$
Interpretation of our findings must be cautious because of the small sample size, preventing us from adjusting for potential confounders (including age) and reducing the generalizability of our results. This is a limitation common to most autopsy studies in a clinical trial as the numbers are generally low ${ }^{7}$, as compared to large-scale population-based studies. In addition, we cannot rule out the possibility that there may have been a greater interest among patients, researchers and clinicians to pursue an autopsy when the clinical presentation was atypical or uncertain, resulting in selection bias for cases with mixed pathology. Furthermore, as a retrospective autopsy study, we cannot rule out the development of new pathology from the last assessment to death; however, given that patients with mixed pathology had lower initial FRS performance in select subcategories, we suspect that the observed mixed pathology was already present at the patients' first visit. In the patient with an inflammatory pseudotumor, it is likely that the pseudotumor developed after the last clinical visit as previous brain imaging was unremarkable other than volume loss. A larger scale prospective study using biomarkers capable of identifying each type of dementia pathology will be needed to provide more definitive answers with respect to the timing of the onset of pathologies in mixed AD.

In most clinical trials, brain imaging is required to rule out significant cerebrovascular ischemic changes prior to enrolment. In our current cohort, although all subjects had brain imaging performed prior to their clinical diagnosis of $\mathrm{AD}$, only $4 / 10$ subjects with mixed $\mathrm{AD} / \mathrm{VaD}$ or $\mathrm{AD} / \mathrm{VaD} / \mathrm{DLB}$ had white matter abnormalities documented on the radiologist report, while 2/5 subjects with pure AD had mild white matter changes noted on brain CT. It is possible that CT is not sensitive enough to identify white matter ischemic changes in our subjects, and MRI should be the preferred imaging modality over CT because of its enhanced detection of tissue contrast, white matter changes, as well as brain atrophy. ${ }^{25,26}$ Ideally, future clinical trials and research studies should ensure that all subjects have neuroimaging done within a reasonable period of time (one year) prior to inclusion in studies to rule out vascular causes of cognitive impairment.

We speculate that there may be several potential benefits to be able to discern pure AD from dementia secondary to other pathological processes; for instance, the accurate diagnosis of vascular dementia may lead to tighter management of cardiovascular risk factors in order to prevent further cognitive decline. However, the limited evidence available to date do not clearly demonstrate that control of vascular risk factors such as diabetes, ${ }^{27}$ hypertension, ${ }^{28}$ hyperhomocysteinemia, ${ }^{29}$ or dyslipidemia $^{28}$ leads to better cognitive test performance or lower incidence of dementia. It has been suggested that the absence of benefit may be due to the time-delay of treatment initiated late in life, while management of these vascular risk factors during midlife may hold better promise than treatment late in life..$^{30,31}$

The presence of mixed pathology may also reduce the effectiveness of disease-modifying interventions for $\mathrm{AD}$. We hypothesize that patients with coexisting vascular or Lewy body pathology may not respond as well to current $\mathrm{AD}$ experimental treatments including amyloid lowering agents compared to those with pure AD. In a case report of a subject immunized with AN- 
1792, it appears that amyloid pathology can been reduced, but other pathologies including neurofibrillary tangles (tau) and Lewy body ( $\alpha$-synuclein) remain. ${ }^{32}$ We can only speculate how mixed pathology has impacted on other clinical trials to date.

Despite significant differences in the baseline FRS of pure and mixed $\mathrm{AD}$, more sensitive and specific diagnostic tools are required to differentiate between dementia with pure and mixed pathology in research trials as well as clinical practice. The current available biomarkers for AD such as cerebrospinal fluid amyloid and tau, and Pittsburgh compound B Positron Emission Tomography (PiB PET) increases the diagnostic certainty of AD pathology, but do not rule out the presence of other dementia pathology. Further research on pre-mortem biomarkers and improved imaging modalities of all dementia pathologies will be needed in order to advance our ability to discern between pure and mixed $\mathrm{AD}$. Until then, mixed $\mathrm{AD}$ remains a diagnostic challenge.

\section{ACKNOWLEDGEMENTS}

The authors thank Manuela Novello (secretary in the UBCHCARD) for assistance with locating patient charts and the patients and their family as well as the $\mathrm{AD} /$ dementia specialists in UBCH-CARD for assistance with this research.

\section{CONTRIBUTIONS OF AUTHORSHIP}

Mr. Wang: design and conceptualization of the study, collection of data, analysis and interpretation of the data, drafting and revising the manuscript. Ms. Lu: analysis and interpretation of the data, drafting and revising the manuscript. Dr. Mackenzie: reviewed neuropathological data, interpretation of the data, revising the manuscript. Ms. Assaly: collection and interpretation of the data, revising the manuscript. Dr. Jacova: interpretation of the data, revising the manuscript. Dr. Lee: collection and interpretation of data, revising the manuscript. Dr. Beattie: conceptualization of the study, interpretation of the data, revising the manuscript. Dr. Hsiung: design and conceptualization of the study, collection of data, interpretation of the data, drafting and revising the manuscript.

\section{Disclosure / COMPETING INTERESTS}

Mr. Wang is a medical student at UBC and received funds by the Albert and Mary Steiner Summer Research Award and the Canadian Institutes for Health Research (Professional Student Research Award).

Ms. Lu is funded by the Canadian Institutes of Health Research (Canada Graduate Scholarship: Master's Award) and the Multiple Sclerosis Society of Canada (MSc and PhD Research Studentships).

Dr. Jacova is supported by funds from the Fisher Professorship by the Alzheimer Society of British Columbia. She is co-investigator in the Alzheimer's Drug Therapy Initiative (ADTI) project funded by the BC Ministry of Health Services.

Dr. Lee has received honoraria for speaking and participating in advisory boards for Janssen-Ortho, Novartis and Pfizer. He is a co-investigator in the ADTI project funded by the BC Ministry of Health Services. He is supported by the Fisher Professorship through the Alzheimer's Society of British Columbia and he has received funds from the St. Paul's Hospital Foundation and the Cullen Family.
Dr. Beattie is an independent researcher and has participated in multi centre clinical trials sponsored by Hoffman LaRoche, Novartis, Janssen-Ortho, Pfizer, Elan, Bristol-Myers Squibb, GlaxoSmithKline, Ono, Sanofi, and Myriad. She is a coinvestigator in the Alzheimer's Diseases Therapy Initiative funded by the BC Ministry of Health Services.

Dr. Hsiung is supported by a CIHR Clinical Genetics Investigatorship and funds from the Fisher Professorship by the Alzheimer Society of British Columbia. Currently a site investigator for clinical trials sponsored by Baxter, BristolMyers Squibb, Elan, Janssen, and Pfizer. Previously participated in clinical trials by GlaxoSmithKline, Novartis, Myriad, Ono, and Sanofi. Co-investigator in the ADTI project funded by the BC Ministry of Health Services.

\section{REFERENCES}

1. Schneider JA, Arvanitakis Z, Bang W, et al. Mixed brain pathologies account for most dementia cases in communitydwelling older persons. Neurology. 2007;69(24):2197-204.

2. Kovacs GG, Alafuzoff I, Al-Sarraj S, et al. Mixed brain pathologies in dementia: the BrainNet Europe consortium experience. Dement Geriatr Cogn Disord. 2008;26(4):343-50.

3. Sonnen JA, Santa Cruz K, Hemmy LS, et al. Ecology of the aging human brain. Arch Neurol. 2011;68(8):1049-56.

4. O'Brien JT, Erkinjuntti T, Reisberg B, et al. Vascular cognitive impairment. Lancet Neurol. 2003;2(2):89-98.

5. McKeith I, Mintzer J, Aarsland D, et al. Dementia with Lewy bodies. Lancet Neurol. 2004;3(1):19-28.

6. Dubois B, Feldman HH, Jacova C, et al. Revising the definition of Alzheimer's disease: a new lexicon. Lancet Neurol. 2010;9(11): 1118-27.

7 Holmes C, Boche D, Wilkinson D, et al. Long-term effects of Abeta42 immunisation in Alzheimer's disease: follow-up of a randomised, placebo-controlled phase I trial. Lancet. 2008;372 (9634):216-23.

8. Alafuzoff I, Helisalmi S, Heinonen EH, et al. Selegiline treatment and the extent of degenerative changes in brain tissue of patients with Alzheimer's disease. Eur J Clin Pharmacol. 2000;55(1112):815-19.

9. McKhann G, Drachman D, Folstein M, et al. Clinical diagnosis of Alzheimer's disease: report of the NINCDS-ADRDA Work Group under the auspices of Department of Health and Human Services Task Force on Alzheimer's Disease. Neurology. 1984; 34(7):939-44.

10. Gelinas I, Gauthier L, McIntyre M, et al. Development of a functional measure for persons with Alzheimer's disease: the disability assessment for dementia. Am J Occup Ther. 1999;53 (5):471-81

11. Lanctot KL, Hsiung GY, Feldman HH, et al. Assessing the validity of deriving clinical dementia rating (CDR) global scores from independently-obtained functional rating scale (FRS) scores in vascular dementia with and without Alzheimer's disease. Int J Geriatr Psychiatry. 2009;24(10):1174-6.

12. Feldman H, Levy AR, Hsiung GY, et al. A Canadian Cohort Study of Cognitive Impairment and Related Dementias (ACCORD): study methods and baseline results. Neuroepidemiology. 2003; 22:265-74

13. Woodward M, Mackenzie IRA, Hsiung GY, et al. Multiple brain pathologies in dementia are common. Eur Geriatr Med. 2010;1: 259-65.

14. Wisniewski HM, Silverman W. Diagnostic criteria for the neuropathological assessment of Alzheimer's disease: current status and major issues. Neurobiol Aging. 1997;18(4 Suppl): S43-50

15. Newell KL, Hyman BT, Growdon JH, et al. Application of the National Institute on Aging (NIA)-Reagan Institute criteria for the neuropathological diagnosis of Alzheimer disease. J Neuropathol Experimental Neurol. 1999;58(11):1147-55. 
16. McKeith IG, Fairbairn AF, Bothwell RA, et al. An evaluation of the predictive validity and inter-rater reliability of clinical diagnostic criteria for senile dementia of Lewy body type. Neurology. 1994;44(5):872-7.

17. Munoz DG. The pathological basis of multi-infarct dementia. Alzheimer Dis Assoc Disord. 1991;5(2):77-90.

18. Jellinger KA, Attems J. Is there pure vascular dementia in old age? J Neurol Sci. 2010;299(1-2):150-4.

19. Cairns NJ, Taylor-Reinwald L, Morris JC. Autopsy consent, brain collection, and standardized neuropathologic assessment of ADNI participants: the essential role of the neuropathology core. Alzheimers Dement. 2010;6(3):274-9.

20. Esiri MM, Nagy Z, Smith MZ, et al. Cerebrovascular disease and threshold for dementia in the early stages of Alzheimer's disease. Lancet. 1999;354(9182):919-20.

21. Jellinger KA, Attems J. Prevalence and impact of cerebrovascular pathology in Alzheimer's disease and parkinsonism. Acta Neurol Scand. 2006;114(1):3846.

22. Reed BR, Mungas DM, Kramer JH, et al. Profiles of neuropsychological impairment in autopsy-defined Alzheimer's disease and cerebrovascular disease. Brain. 2007;130(Pt 3): 731-9.

23. McGuinness B, Barrett SL, Craig D, et al. Executive functioning in Alzheimer's disease and vascular dementia. Int $\mathrm{J}$ Geriatr Psychiatry. 2010;25(6):562-8.

24. Baillon S, Muhommad S, Marudkar M, et al. Neuropsychological performance in Alzheimer's disease and vascular dementia: comparisons in a memory clinic population. Int $\mathrm{J}$ Geriatr Psychiatry. 2003;18(7):602-8.
25. Tartaglia MC, Rosen HJ, Miller BL. Neuroimaging in dementia. Neurotherapeutics. 2011;8(1):82-92.

26. Whitwell JL, Jack CR, Jr. Neuroimaging in dementia. Neurol Clin. 2007;25(3):843, 57, viii.

27. ADVANCE Collaborative Group, Patel A, MacMahon S, et al. Intensive blood glucose control and vascular outcomes in patients with type 2 diabetes. N Engl J Med. 2008;358(24): 2560-72.

28. Ligthart SA, Moll van Charante EP, Van Gool WA, et al. Treatment of cardiovascular risk factors to prevent cognitive decline and dementia: a systematic review. Vasc Health Risk Manag. 2010; 7(6):775-85.

29. Shepherd J, Blauw GJ, Murphy MB, et al. Pravastatin in elderly individuals at risk of vascular disease (PROSPER): a randomised controlled trial. Lancet. 2002 Nov 23;360(9346): 1623-30.

30. Gorelick P, Scuteri A, Black SE, et al. Vascular contributions to cognitive impairment and dementia: a statement for healthcare professionals from the American Heart Association/American Stroke Association. Stroke. 2011;42(9):2672-713.

31. Vuorinen M, Solomon A, Rovio S, et al. Changes in vascular risk factors from midlife to late life and white matter lesions: a 20year follow-up study. Dement Geriatr Cogn Disord. 2011;31(2): $119-25$

32. Bombois S, Maurage CA, Gompel M, et al. Absence of betaamyloid deposits after immunization in Alzheimer disease with Lewy body dementia. Arch Neurol. 2007;64(4):583-7. 